\title{
Simulasi Numerik Sistem Water Oil Separator Menggunakan Software Dinamika Fluida
}

\author{
Ihat Solihat ${ }^{1 \text { a) }}$, Afif Suma Prasetyo ${ }^{1}$, Perdamean Sebayang ${ }^{2}$, Anggito Pringgo \\ Tetuko $^{2}$,Achmad Maulana Soehada Sebayang ${ }^{1}$, dan Mohamad Nasrun ${ }^{1}$ \\ ${ }^{1}$ Program Studi Teknik Mesin, Universitas Pamulang, Jl. Surya Kencana No.1, Pamulang 15417, Tangerang \\ Selatan, Indonesia \\ ${ }^{2}$ Pusat Penelitian Fisika, Badan Riset Indonesia, Serpong 15314, Tangerang Selatan, Indonesia
}

E-mail: ${ }^{a)}$ dosen00990@unpam.ac.id

\author{
Received : 21 September $2021 \quad$ Revision :12 Oktober $2021 \quad$ Accepted:20 November 2021
}

\begin{abstract}
Abstrak: Computational fluid dyanamic (CFD) digunakan sebagai simulasi untuk memodelkan pemisahan multiphase dalam desain pemisahan diseparator. Dalam penelitian ini bertujuan untuk mengetahui pengaruh variasi kecepatan air dan minyak pada sistem water- oil separator, untuk mengetahui distribusi (kontur) kecepatan air dan minyak pada inlet sistem water-oil separator, untuk mengetahui distribusi (kontur) tekanan pada outlet dengan tekanan pada sistem water-oil separator. Dalam penelitian ini memiliki batasan pada fluida yang digunakan jenis dua fasa minyak dan air, mengunakan model aliran multiphase, pressure outlet yang digunakan 0,1 bar, tipe meshing yang digunakan tipe tetrahedral dengan ukuran $5 \mathrm{~mm}$. Metode yang digunakan dalam analisa tersebut adalah perhitungan analitik dengan simulasi Computational Fluid Dyanamic (CFD). Terdapat variasi kecepatan inlet yaitu $0,264 \mathrm{~m} / \mathrm{s}, 0,4 \mathrm{~m} / \mathrm{s}, 0,528 \mathrm{~m} / \mathrm{s}, 0,664 \mathrm{~m} / \mathrm{s}, 0,8 \mathrm{~m} / \mathrm{s}$. dengan tekanan outlet 0,1 bar dengan kecepatan inle sebesar $0,264 \mathrm{~m} / \mathrm{s}, 0,4 \mathrm{~m} / \mathrm{s}, 0,528 \mathrm{~m} / \mathrm{s}, 0,664 \mathrm{~m} / \mathrm{s}, 0,8 \mathrm{~m} / \mathrm{s}$. Dari pengujian dengan simulasi simscale dapat disimpulkan bahwa kecepatan terrendah terdapat pada variasi $0,264 \mathrm{~m} / \mathrm{s}$ dengan kecepatan maksium dapat mencapai $0.023 \mathrm{~m} / \mathrm{s}$ dan kecepatan tertinggi terdapat pada variasi $0,8 \mathrm{~m} / \mathrm{s}$ dengan kecepatan maksimum $0.071 \mathrm{~m} / \mathrm{s}$. Pada tekanan pada outlet tekanan yang paling rendah sebesar $147393 \mathrm{~Pa}$, pada variasi kencepatan inlet $0,264 \mathrm{~m} / \mathrm{s}$, dan tertingi tekanan outlet pada variasi $0,8 \mathrm{~m} / \mathrm{s}$ sebesar $446590 \mathrm{~Pa}$. Pengaruh kecepatan minyak dan air juga mempengaruhi pola aliran fluida menjadi turbulen dan mengakibatkan pemisahan menjadi cepat.
\end{abstract}

Kata Kunci: Computational Fluid Dynamics (CFD), Distribusi Contur, Kecepatan, dan Tekanan.

\begin{abstract}
Computational fluid dynamics (CFD) was used as a simulation to model multiphase separation in the separator design. This study aims to determine the effect of variations in air and oil velocity on the water-oil separator system, to determine the distribution (contour) of air and oil velocity at the water-oil separator inlet system, to determine the distribution (contour) of pressure at the outlet with pressure on the system. water-oil separator. In this study, the fluid used is two-phase oil and water, using a multiphase flow model, the outlet pressure used is 0.1 bar, the meshing type used is a tetrahedral type with a size of $5 \mathrm{~mm}$. The method used in the analysis is an analytical calculation with computational fluid dynamics (CFD) simulation. There are variations in the inlet speed, namely $0.264 \mathrm{~m} / \mathrm{s}, 0.4 \mathrm{~m} / \mathrm{s}, 0.528 \mathrm{~m} / \mathrm{s}, 0.664 \mathrm{~m} / \mathrm{s}, 0.8$ $\mathrm{m} / \mathrm{s}$. with an outlet pressure of 0.1 bar with an inle velocity of $0.264 \mathrm{~m} / \mathrm{s}, 0.4 \mathrm{~m} / \mathrm{s}, 0.528 \mathrm{~m} / \mathrm{s}, 0.664 \mathrm{~m} / \mathrm{s}, 0.8 \mathrm{~m} / \mathrm{s}$. From testing with simscale simulation, it can be simulated that the lowest speed is found in variations of $0.264 \mathrm{~m} / \mathrm{s}$ with a maximum speed of $0.023 \mathrm{~m} / \mathrm{s}$ and the highest speed is found in variations of $0.8 \mathrm{~m} / \mathrm{s}$ with a maximum speed of $0.071 \mathrm{~m} / \mathrm{s}$. At the pressure at the outlet the lowest pressure is $147393 \mathrm{~Pa}$, the inlet velocity variation is $0.264 \mathrm{~m} / \mathrm{s}$, and the highest pressure at the outlet is at a variation of $0.8 \mathrm{~m} / \mathrm{s}$ is $446590 \mathrm{~Pa}$. The effect of oil and air velocity also affects the fluid flow pattern to become turbulent and result in rapid separation.
\end{abstract}

Keywords: Computational Fluid Dynamics (CFD), Contours Distribution, Velocity, and Pressure. 


\section{PENDAHULUAN}

Permintan minyak serta gas terus meninngkat bersamaan dengan populasi didunia serta pertumbuhan teknologi. Sekitar $80 \%$ dari kebutuhan dunia menggunakan bahan bakar fosil pada tahun 2010. Minyak mentah pada umumnya dibuat dalam wujud emulsi air serta minyak. sebelum menjadi produk yang berharga, pengolahan minyak dilakukan dengan cara kimia, listrik serta mekanik umumnya digunakan untuk memisahkan fase air serta minyak. Permodelan serta simulasi digunakan untuk mengurangi waktu serta biaya dalam desain separator. Computational fluid dyanamic (CFD) merupakan perlengkapan yang bermanfaat yang bisa membagikan hasil yang normal dari pengetahuan serta pemikiran kedepan tentang sikap aliran bila simulasi diatur dengan tepat. Computational fluid dyanami (CFD) digunakan untuk mevalidasi serta membagikan kriteria yang lebih baik untuk membuat desain separator [1].

Computational fluid dyanamic (CFD) digunakan sebagai alat untuk memodelkan pemisahan multiphase secara gravitasi horizontal serta digunakan dalam desain pemisah melalui studi retrofit. pemisah ini merupakan unit operasi pertama dihilir produksi minyak untuk memisahkan produksi air, gas dan minyak mentah secara kritis. Studi awal tentang CFD melibatkan pemecahan pemisah air dan minyak menjadi beberapa wilayah yang dianalisis secara terpisah. Pemisahan air dan minyak dimodelkan menggunakan model multiphase dengan medan kecepatan dan vikositas yang ditentukan emulsinya. serta didasarkan pada vikositas oli dengan fraksi volume air. penggunaan vikositas campuran dengan volume ini telah digunakan secara konsisten dan dapat dipahami dengan baik bahwa emulsi air dalam minyak menunjutkan peningkatan vikositas nyata atau efektif dengan fraksi fasa air yang dapat menjadi lebih besar dari pada viskositas masa minyak secara kontinu yang dapat mempengaruhi prediksi pemisah air dan minyak [2].

Fluida adalah zat yang dapat bergerak jika diberikan gaya. fluida dapat berubah bentuk dan tidak permanen. fluida membentuk berbagai jenis padatan sesuai dengan bentuk benda yang dilaluinya. Karakteristik aliran fluida meliputi tekanan statis, tekanan dinamis, tekanan total, kecepatan fluida, dan tegangan geser [3].

Debit aliran adalah laju aliran fluida atau kecepatan aliran fluida yang menyatakan besaran volume fluida yang mengalir dalam satuan waktu [3].

$$
\begin{aligned}
& Q=\frac{V}{t} \ldots \ldots \ldots(1) \\
& \text { Atau: } \\
& Q=A v \ldots \ldots \ldots(2)
\end{aligned}
$$

Dimana :

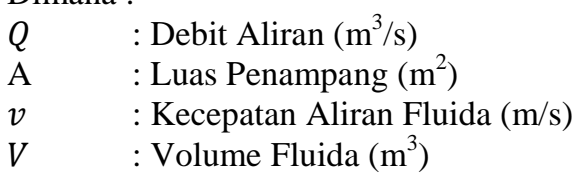

Persamaan kontinuitas menggambarkan hubungan antara kecepatan fluida yang masuk ke dalam pipa dan kecepatan fluida yang keluar dari pipa [3].

$$
\begin{aligned}
& Q 1=Q 2 \ldots \ldots \ldots \ldots \ldots \\
& A_{1} v_{1}=A_{2} v_{2} \ldots \ldots \ldots(4)
\end{aligned}
$$

Dimana :

$$
\begin{array}{ll}
A_{1} & : \text { Luas Penampang } 1\left(\mathrm{~m}^{2}\right) \\
v_{1} & : \text { Kecepatan Aliran Fluida } 1(\mathrm{~m} / \mathrm{s}) \\
A_{2} & : \text { Luas Penampang } 2\left(\mathrm{~m}^{2}\right) \\
v_{2} & : \text { Kecepatan Aliran Fluida } 2(\mathrm{~m} / \mathrm{s})
\end{array}
$$

Bilangan Reynolds digunakan untuk menentukan sifat utama aliran, apakah aliran Aliran laminar, aliran transisi atau turbulen dan posisinya pada skala menunjukkan kepentingan relatif aliran turbulen dibandingkan dengan aliran laminar.bilangan Reynolds dinyatakan dengan [4]. 


$$
R e=\frac{\rho v D}{\mu}
$$

Dimana :

$$
\begin{array}{ll}
\rho & : \text { Massa Jenis Fluida }\left(\mathrm{Kg} / \mathrm{m}^{3)}\right. \\
v & : \text { Kecepatan Aliran Fluida }(\mathrm{m} / \mathrm{s}) \\
D & : \text { Diameter Pipa }(\mathrm{m}) \\
\mu & : \text { Viskositas Dinamik }\left(\mathrm{Ns} / \mathrm{m}^{2}\right)
\end{array}
$$

Persamaan Bernoulli adalah persamaan yang menunjukkan bahwa peningkatan kecepatan fluida juga mempengaruhi penurunan tekanan fluida. Persamaan Bernoulli memberikan hubungan antara tekanan, kecepatan, dan posisi atau ketinggian dua titik kerapatan dalam medan aliran [5].

$$
P+\rho g h+\frac{1}{2} \rho v^{2}=\text { Konstan }
$$

\section{Dimana :}

$$
\begin{array}{ll}
P & : \text { Tekanan Fluida }(\mathrm{Pa}) \\
\rho & : \text { Massa Jenis Fluida }\left(\mathrm{Kg} / \mathrm{m}^{3}\right) \\
g & : \text { Percepatan Gravitasi }\left(\mathrm{m} / \mathrm{s}^{2}\right) \\
h & : \text { Head / Tinggi Elevasi }(\mathrm{m}) \\
v & : \text { Kecepatan Aliran Fluida }(\mathrm{m} / \mathrm{s})
\end{array}
$$

Diameter hidrolik adalah empat kali luas penampang aliran dibagi dengan keliling basah (P) pipa. Diameter hidrolik mewakili panjang karakteristik yang mendefinisikan dimensi penampang dari bentuk tertentu. Faktor 4 ditambahkan ke definisi Dh. Sehingga diameter hidrolik tabung penampang persegi sama dengan diameter tabung penampang lingkaran [6].

$$
D_{h}=\frac{4\left(\pi D^{2} / 4\right)}{\pi D}=D
$$

Dimana :

$$
\begin{array}{ll}
D & : \text { Diameter Pipa (m) } \\
\pi & : \text { Phi }(3,14 \text { atau 22/7) }
\end{array}
$$

$$
D_{h}=\frac{2(a b)}{(a+b)} \ldots \ldots \ldots \ldots \ldots
$$

Dimana :

$$
\begin{array}{ll}
a & \text { : Tinggi Diameter } \\
b & \text { : Panjang Diameter }
\end{array}
$$

Separator adalah bejana tekan yang digunakan untuk memisahkan campuran fluida berdasarkan perbedaan kepadatan. Separator memiliki dua jenis pemisah yaitu separator dua fasa (two phase) dan tiga fasa (three phase) [7].

Penelitian ini bertujuan untuk permodelan distribusi pemisah air dan minyak dan Untuk mengetahui pengaruh variasi kecepatan air, distribusi (kontur) kecepatan pada sistem water- oil separator, distribusi (kontur) tekanan pada sistem water-oil separator 


\section{METODOLOGI}

Metodologi penelitan adalah cara mengetahui sesuatu untuk menemukan,mengembangkan atau menguji kebenaran secara sistematik,logis dan empiris mengunakan metode ilmiah [8].

Pada penelitian ini dilakukan secara numerik dengan metode Computer Fluid Dynamic (CFD) menggunakan software simscale. dengan menggunakan perangkat Komputer core i5-2500 dengan spesifikasi prosesor @3.300 GHZ, VGA 1 GB,64 BIT, RAM 4 GB, DDR3, HDD 500 GB. Pada simulasi ini menggunakan model Volume Of Fluid (VOF), dengan jenis aliran turbulen RNG k-e, dan kondisi steady. Simulasi ini menggunakan fluida air dan minyak, dengan variasi kecepatan inlet air dan kecepatan inlet minyak.

Tabel 1. Data Geometri Pada Separator

\begin{tabular}{lc}
\hline Spesifikasi & Ukuran $(\mathrm{m})$ \\
\hline Water-Oil Separator & $0,5 \times 0,2 \times 0,2$ \\
Baffle 1 & $0,2 \times 0,13$ \\
Baffle 2 & $0,2 \times 0,10$ \\
Diameter Water-Oil Mixture Inlet & 0,0127 \\
Diameter Water Outlet & 0,0127 \\
Diameter Oil Outlet & 0,0127 \\
\hline
\end{tabular}

Tabel 2. Data Material Air Dan Pertamina Dex

\begin{tabular}{lcc}
\hline Material & Densitas $\left(\mathrm{kg} / \mathrm{m}^{3}\right)$ & Viskositas kinematic $\left(\mathrm{m}^{2} / \mathrm{s}\right)$ \\
\hline Air & 997,3 & $9.338 \mathrm{e}-7$ \\
Pertamina dex & 820 & 2 \\
\hline
\end{tabular}

Tabel 3. Variasi Kecepatan

\begin{tabular}{cc}
\hline No simulasi & Kecepatan $(\mathrm{m} / \mathrm{s})$ \\
\hline 1 & 0,264 \\
2 & 0,4 \\
3 & 0,528 \\
4 & 0,664 \\
5 & 0,8 \\
\hline
\end{tabular}

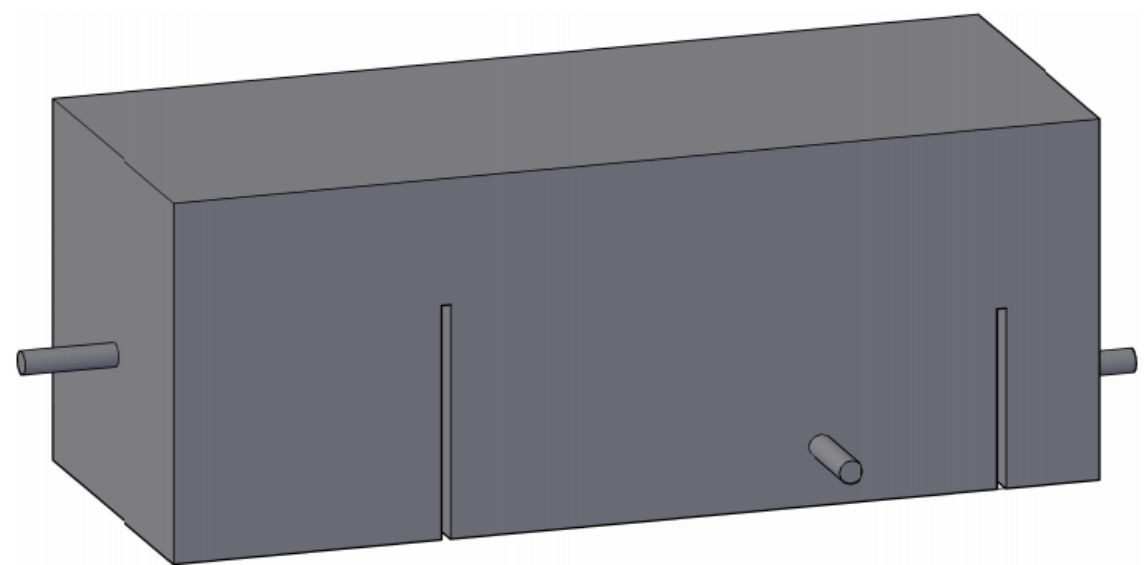

Gambar 1. Desain separator 


\section{HASIL DAN PEMBAHASAN}

Dari hasil pengujian didapatkan hasil simulasi distribusi kecepatan dan tekanan menggunakan software simscale.
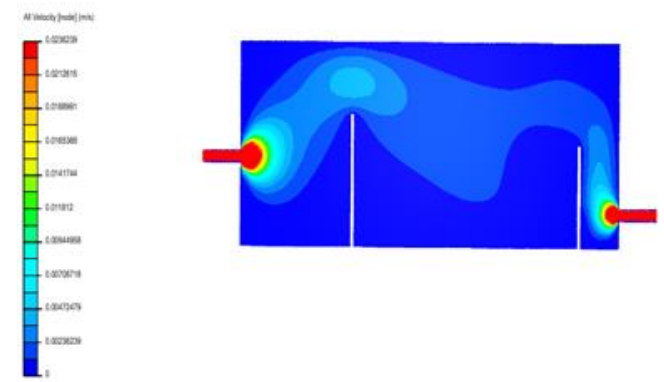

Gambar 2. Simulasi kontur kecepatan 0,264 m/s
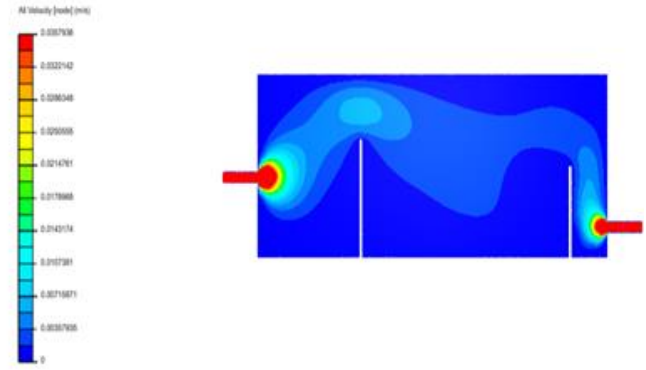

Gambar 3. Simulasi kontur kecepatan $0,4 \mathrm{~m} / \mathrm{s}$

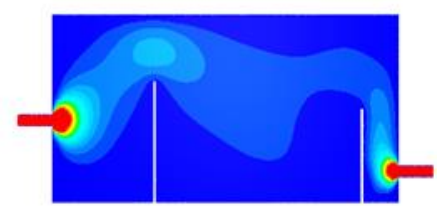

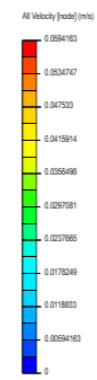

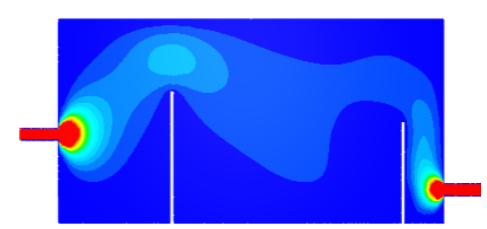

Gambar 5. Simulasi kontur kecepatan 0,664 m/s
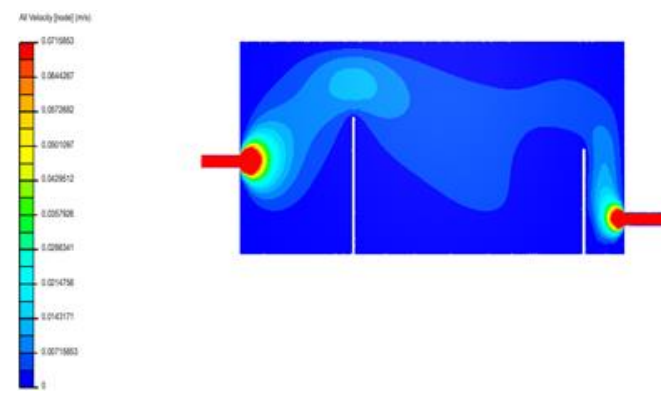

Gambar 6. Simulasi kontur kecepatan $0,8 \mathrm{~m} / \mathrm{s}$

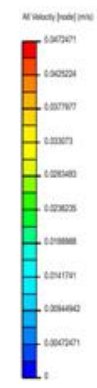

Gambar 4. Simulasi kontur kecepatan $0,528 \mathrm{~m} / \mathrm{s}$

Hasil simulasi kontur velocity dengan variasi kecepatan 0,264, 0,4, 0,528, 0,664 0,8 m/s menunjukan kontur kecepatan fluida pertamina dex dan air dimana kecepatan tinggi terjadi pada sisi inlet, outlet air dan outlet minyak. Pada saat fluida dialirkan kecepatan fluida mengalami penurunan kecepatan. Dimana aliran menunjukan turbulen sehingga mengakibatkan pemisahan antara fluida minyak dan air menjadi cepat. Untuk fluida air akan berada paling bawah karena mempunyai densitas yang tinngi dan bergerak menuju outlet air. Sedangkan pada fluida minyak (pertamina dex) akan bergerak melwati baffle kedua tetesan minyak akan jatuh kebawah menuju outlet minyak (pertamina dex).

Dari simulasi Gambar 2,3,4,5,6 dapat disimpulkan semakin kecil ukuran diameter, maka nilai kecepatan aliran semakin besar, namun semakin besar ukuran diameter maka semakin kecil nilai kecepatan aliran. Sesuai dengan asas kontinuitas hukum bernouli [9].

Pada grafik kecepatan terhadap panjang aksial, data ini diambil dari hasil simulasi pada kontur pressure dengan beberapa variasi kecepatan di inlet, dengan variasi kecepatan inlet $0,264 \mathrm{~m} / \mathrm{s}$, dengan variasi kecepatan inlet $0,4 \mathrm{~m} / \mathrm{s}$, dengan variasi kecepatan inlet $0,528 \mathrm{~m} / \mathrm{s}$, dengan variasi kecepatan inlet $0,664 \mathrm{~m} / \mathrm{s}$, dengan variasi kecepatan inlet $0,8 \mathrm{~m} / \mathrm{s}$, diolah menjadi grafik. 


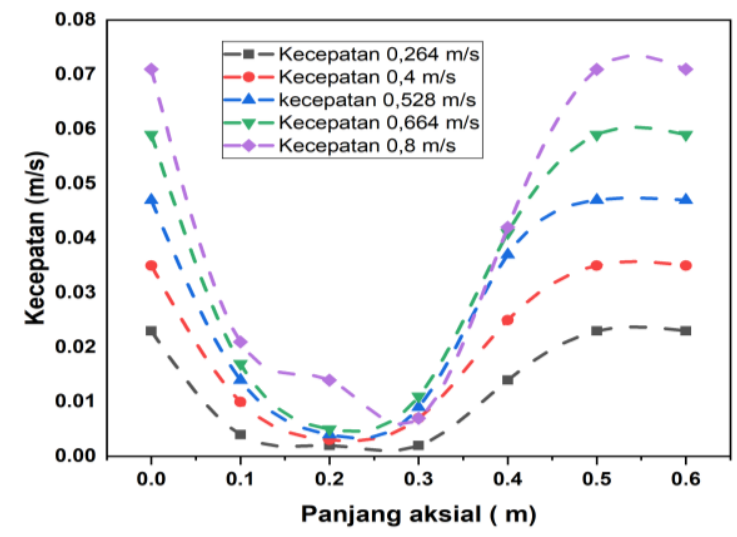

Gambar 7. Grafik Kecepatan (Velocity) Terhadap Panjang Aksial

Dari grafik kecepatan terhadap panjang aksial dimana pada pada saluran inlet nilai kecepatan aliran tinggi dan semakin bertambahnya panjang aksial maka kecepatan aliran semakin rendah dan pada saat aliran menuju outlet mengalami kenaikan kecepatan dikarenakan diameter semakin kecil. Sesuai dengan asas kontinuitas dimana semakin kecil ukuran diameter, maka nilai kecepatan aliran semakin besar, namun semakin besar ukuran diameter maka semakin kecil nilai kecepatan aliran.
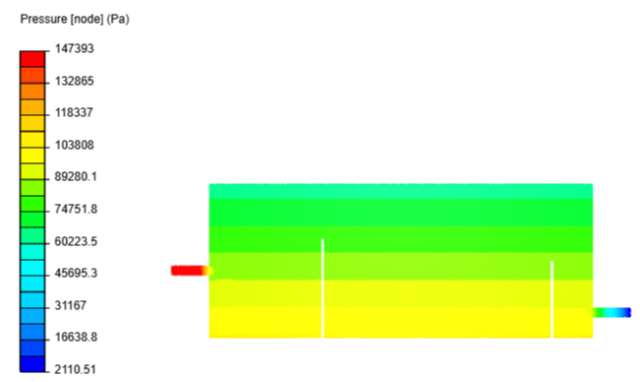

Gambar 8. Simulasi kontur pressure 0,1 bar dengan kecepatan $0,264 \mathrm{~m} / \mathrm{s}$

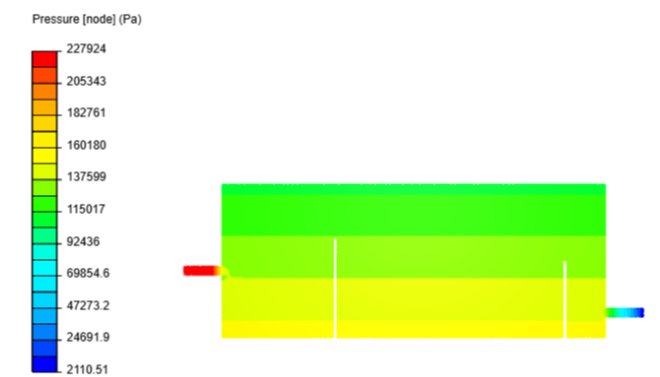

Gambar 9. Simulasi kontur pressure 0,1 bar dengan kecepatan $0,4 \mathrm{~m} / \mathrm{s}$

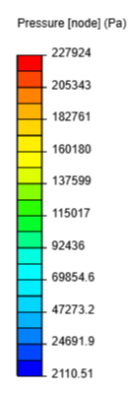

Gambar 10. Simulasi kontur pressure 0,1 bar dengan kecepatan $0,528 \mathrm{~m} / \mathrm{s}$
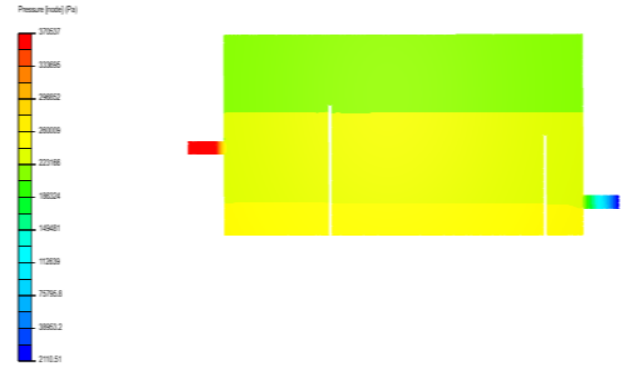

Gambar 11. Simulasi kontur pressure 0,1 bar dengan kecepatan $0,664 \mathrm{~m} / \mathrm{s}$
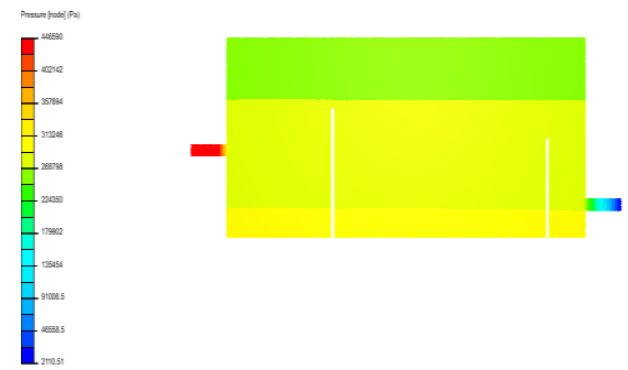

Gambar 12. Simulasi kontur pressure 0,1 bar dengan kecepatan $0,8 \mathrm{~m} / \mathrm{s}$ 
Pada Gambar 8,9,10,11,12 menujukan counturs pressure tertinggi terdapat pada daerah inlet separator saat memasuki media separator dan melawati baffle satu dan dua pressure aliran lebih kecil dan mengakibatkan tekanan pada separator menjadi stabil. Setelah memasuki outlet minyak dan air pressure aliran rendah.

Dari simulasi counturs pressure dapat disimpulkan bahwa semakin tinggi kecepatan aliran maka tekanan semakin rendah sesuai hukum bernouli.

Pada grafik pressure terhadap panjang aksial, data ini diambil dari hasil simulasi pada kontur pressure dengan beberapa variasi pressure outlet 0.1 bar dengan kecepatan inlet 0,264 , variasi pressure outlet 0.1 bar dengan kecepatan inlet $0,4 \mathrm{~m} / \mathrm{s}$, beberapa variasi pressure outlet 0.1 bar dengan kecepatan inlet $0,528 \mathrm{~m} / \mathrm{s}$ beberapa variasi pressure outlet 0.1 bar dengan kecepatan inlet $0,664 \mathrm{~m} / \mathrm{s}$, beberapa variasi pressure outlet 0.1 bar dengan kecepatan inlet $0,8 \mathrm{~m} / \mathrm{s}$, diolah menjadi grafik.

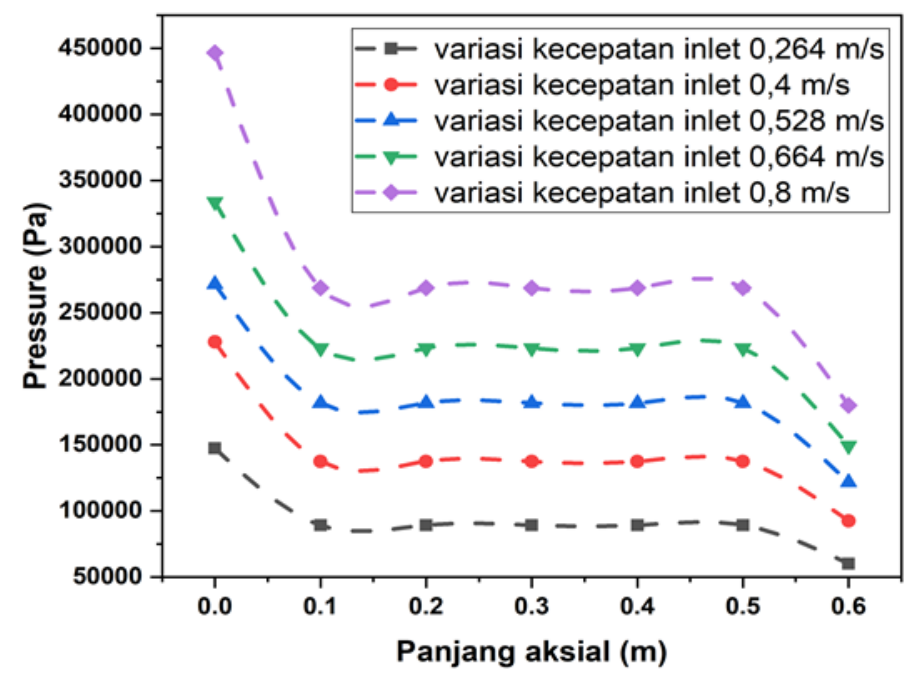

Gambar 13. Grafik Tekanan (Pressure) Terhadap Panjang Aksial

Dari grafik diatas dapat disimpulkan bahwa bertambahnya panjang separator maka tekanan mengalami penurunan dikarenakan semakin besar luas penampamg maka tekanan semakin kecil. Sesuai dengan hukum bernaouli.

\section{KESIMPULAN}

Dari hasil kesimpulan yang telah dilakukan dapat diambil beberapa kesimpulan sebagai berikut:

1. Pada kecepatan minyak dan air dengan variasi kecepatan $0,264 \mathrm{~m} / \mathrm{s}, 0,4 \mathrm{~m} / \mathrm{s}, 0,528 \mathrm{~m} / \mathrm{s}, 0,664 \mathrm{~m} / \mathrm{s}, 0,8$ $\mathrm{m} / \mathrm{s}$ terjadi pengaruh kecepatan maksimum terdapat pada inlet dan outlet, serta penurunan kecepatan terjadi pada saat aliran fluida pada sisi masuk dimana aliran menunjukan turbulen sehingga mengakibatkan pemisahan antara fluida minyak dan air menjadi cepat.

2. Pada distribusi contur dengan variasi kecepatan $0,264 \mathrm{~m} / \mathrm{s}, 0,4 \mathrm{~m} / \mathrm{s}, 0,528 \mathrm{~m} / \mathrm{s}, 0,664 \mathrm{~m} / \mathrm{s}, 0,8 \mathrm{~m} / \mathrm{s}$ didapatkan hasil yaitu variasi kecepatan $0,264 \mathrm{~m} / \mathrm{s}$ medapatkan hasil contur lebih rendah dan hasil contur tertinggi terdapat pada variasi $0,8 \mathrm{~m} / \mathrm{s}$ di inlet dan outlet.

3. Pada distribusi kontur tekanan 0,1 bar dengan variasi kecepatan $0,264 \mathrm{~m} / \mathrm{s}, 0,4 \mathrm{~m} / \mathrm{s}, 0,528 \mathrm{~m} / \mathrm{s}, 0,664$ $\mathrm{m} / \mathrm{s}$ dan $0,8 \mathrm{~m} / \mathrm{s}$ didapatkan hasil yaitu variasi contur tekanan 0,1 bar dengan kecepatan $0,264 \mathrm{~m} / \mathrm{s}$ medapatkan hasil contur tekanan lebih rendah dan hasil kontur tertinggi terdapat pada tekanan 0,1 bar dengan variasi kecepatan $0,8 \mathrm{~m} / \mathrm{s}$ sebesar $446590 \mathrm{~Pa}$. 


\section{UCAPAN TERIMA KASIH}

Penulis mengucapkan terima kasih kepada Program Studi Teknik Mesin-Universitas Pamulang dan Pusat Penelitian Fisika-Lembaga Ilmu Pengetahuan Indonesia atas dukungan dalam penelitian ini..

\section{DAFTAR PUSTAKA}

[1] T. T. Le et al., "Effect of simultaneous three-angular motion on the performance of an air-water-oil separator under offshore operation," Ocean Eng., vol. 171, pp. 469-484, 2019, doi: 10.1016/j.oceaneng.2018.11.012.

[2] L. M. Oshinowo and R. D. Vilagines, "Modeling of Oil-Water Separation Efficiency in Three-Phase Separators: Effect of Emulsion Rheology and Droplet Size Distribution," Chem. Eng. Res. Des., vol. 159, pp. 278-290, 2020, doi: 10.1016/j.cherd.2020.02.022.

[3] J. Jalaluddin, S. Akmal, N. ZA, and I. Ishak, "ANALISA PROFIL ALIRAN FLUIDA CAIR DAN PRESSURE DROP PADA PIPA L MENGGUNAKAN METODE SIMULASI COMPUTATIONAL FLUID DYNAMIC (CFD)," J. Teknol. Kim. Unimal, vol. 8, no. 1, pp. 97-108, 2019, doi: http://dx.doi.org/10.29103/jtku.v8i1.3396.

[4] A. Ghurri, Dasar-Dasar Mekanika Fluida. Jurusan Teknik Mesin Universitas Udayana, 2014.

[5] W. S. Janna, Introduction to Fluid Mechanics, Fourth Edition. CRC Press, 2010.

[6] A. Syuhada, R. Sary, and Z. Zakirullah, "Pengaruh Diameter Hidrolik Terhadap Perpindahan Panas Kolektor Surya Belokan Tajam," J. Tek. Mesin Unsyiah, vol. 7, no. 2, pp. 38-42, 2019, doi: 10.24815/jtm.v7i2.18236.

[7] M. I. Insani, U. A. Prabu, and W. Herlina, "ANALISIS DESAIN UKURAN SEPARATOR PRODUKSI HORIZONTAL DUA FASA UNTUK TARGET PEMISAHAN FLUIDA 25000 BFPD PT.MEDCO E\&P INDONESIA RIMAU ASSET," J. Pertamb., vol. 2, no. 3, pp. 39-49, 2018, doi: https://doi.org/10.36706/jp.v2i3.7401.

[8] Surahman, M. Rachmat, and S. Supardi, Metodologi Penelitian. Kementerian Kesehatan Republik Indonesia, 2016.

[9] B. R. Munson, D. F. Young, T. H. Okiishi, and W. W. Huebsch, Fundamentals of Fluid Mechanics, Sixth Edition. John Wiley \& Sons, Inc, 2009. 